\title{
Microstructures and Mechanical Properties of Al-Ti-Zr-Nb-Ta-Mo-V Refractory High-Entropy Alloys with Coherent B2 Nanoprecipitation
}

\author{
Zhenhua Wang ${ }^{1}$, Dongming Jin ${ }^{1}$, Jincan Han ${ }^{1}$, Qing Wang ${ }^{1, *}$, Zhongwei Zhang ${ }^{2, *}$ and Chuang Dong ${ }^{1}$ \\ 1 Engineering Research Center of High Entropy Alloy Materials (Liaoning Province), \\ Key Laboratory of Materials Modification by Laser, Ion and Electron Beams (Ministry of Education), \\ School of Materials Science and Engineering, Dalian University of Technology, Dalian 116024, China; \\ Ahua@mail.dlut.edu.cn (Z.W.); jdm536824@163.com (D.J.); s554875122y@163.com (J.H.); \\ dong@dlut.edu.cn (C.D.) \\ 2 Institute of Advanced Structure Technology, Beijing Institute of Technology, Beijing 100081, China \\ * Correspondence: wangq@dlut.edu.cn (Q.W.); zhangzhongw@163.com (Z.Z.)
}

check for updates

Citation: Wang, Z.; Jin, D.; Han, J.; Wang, Q.; Zhang, Z.; Dong, C. Microstructures and Mechanical Properties of Al-Ti-Zr-Nb-Ta-Mo-V Refractory High-Entropy Alloys with Coherent B2 Nanoprecipitation. Crystals 2021, 11, 833. https:// doi.org/10.3390/cryst11070833

Academic Editors: Rui Feng, Ke An and Peter K. Liaw

Received: 31 May 2021

Accepted: 14 July 2021

Published: 19 July 2021

Publisher's Note: MDPI stays neutral with regard to jurisdictional claims in published maps and institutional affiliations.

Copyright: (c) 2021 by the authors. Licensee MDPI, Basel, Switzerland. This article is an open access article distributed under the terms and conditions of the Creative Commons Attribution (CC BY) license (https:// creativecommons.org/licenses/by/ $4.0 /)$.

\begin{abstract}
In this work, the microstructural evolution and mechanical properties of new body-centered cubic (BCC)-based Al-Ti-Zr-Nb-Ta-Mo-V refractory high-entropy alloys (RHEAs) with coherent B2 precipitation are investigated. These designed alloy ingots were solid-solutionized at $1573 \mathrm{~K}$ for $2 \mathrm{~h}$ and then aged at $873 \mathrm{~K}$ for $24 \mathrm{~h}$, in which each treatment was followed by water quenching. It was found that there exists phase separation of BCC matrix, Ti/Zr-rich BCC1 and Nb/Ta-rich BCC2 in these alloys. Moreover, ultra-fine spherical B2 nanoparticles with a size of $3 \sim 5 \mathrm{~nm}$ were dispersed in BCC2 matrix. These B2 nanoparticles could be coarsened up to $25 \sim 50 \mathrm{~nm}$ after aging and the particle morphology also changes to a cuboidal shape due to a moderate lattice misfit ( $\varepsilon=0.7 \sim 2.0 \%$ ). Also, $\mathrm{Zr}_{5} \mathrm{Al}_{3}$ phase could coexist with the $\mathrm{B} 2$ phase, where the difference between them is that the Ti element is enriched in $\mathrm{B} 2$ phase, rather than in $\mathrm{Zr}_{5} \mathrm{Al}_{3}$. Among them, the solutionized $\mathrm{Al}_{2} \mathrm{Ti}_{5} \mathrm{Zr}_{4} \mathrm{Nb}_{2.5} \mathrm{Ta}_{2.5}$ RHEAs exhibit good compressive mechanical property with a high yield strength of $1240 \mathrm{MPa}$ and a large plasticity, which is mainly attributed to the coherent precipitation in the BCC matrix.
\end{abstract}

Keywords: high entropy alloy; microstructure; coherent precipitation; mechanical property

\section{Introduction}

In the last decade or so, high-entropy alloys (HEAs) with an equimolar and nearequimolar mixing of multiple principal elements have attracted more attentions owing to the formation of simple crystalline structures and the excellent mechanical properties [1-4]. Especially, refractory HEAs (RHEAs) mainly constituted of early transition metals, such as MoNbTaVW [5], HfNbTaTiZr [6], CrNbTiZr [7], $\mathrm{AlMo}_{0.5} \mathrm{NbTa}_{0.5} \mathrm{Zr}$ [8], $\mathrm{Al}_{0.5} \mathrm{NbTa}_{0.8} \mathrm{~V}_{0.2} \mathrm{Ti}_{1.5} \mathrm{Zr}$ [9], etc., exhibit higher strength within a wide temperature range of 300 1900 K, possessing great potentials for high temperature (HT) applications. This kind of RHEAs are primarily based on the body-centered-cubic (BCC) solid solution structure, where some second phases, such as Laves phase and $\mathrm{M}_{5} \mathrm{Si}_{3}$ phase, are often used to further strengthen the BCC matrix [10-12]. For instance, the compressive yield strength at room temperature (RT) of BCC MoNbTaVW RHEA is $\sigma_{Y S}=1246 \mathrm{MPa}$, and its HT strength at $1873 \mathrm{~K}$ still reaches at $477 \mathrm{MPa}$ [5]. In order to decrease the mass density of alloys, $\mathrm{Al}, \mathrm{Ti}$, $\mathrm{V}$, and $\mathrm{Zr}$ elements could be substituted for Hf, W, and Ta to form a series of light-weight RHEAs, in which the precipitation of second phases on the BCC matrix could enhance the yield strength of alloys up to $1500 \mathrm{MPa}$ at RT. In particular, the coherent precipitation of B2 phase on the BCC matrix would result in the maximum strengthening effect, as evidenced by the fact that the yield strength of Al-Mo-Nb-Ta-Ti-Zr RHEAs exceeds $2000 \mathrm{MPa}$ at RT [8,9].

In fact, it is difficult to achieve the coherent precipitation of B2 on the BCC matrix in RHEAs because the B2 phase is metastable in these systems constituted of $\mathrm{Al}$ and 
early transition metals. However, the appearance of stable Laves phase and $\mathrm{M}_{5} \mathrm{Si}_{3}$-type phases would deteriorate HT strength of RHEAs due to that the non-coherency between the precipitated phase and the matrix could accelerate the coarsening of precipitates. It has demonstrated that the yield strength at $1273 \mathrm{~K}$ of $\mathrm{AlCrNbTiV}$ alloy with a dualphase of $\mathrm{BCC}$ and $(\mathrm{Nb}, \mathrm{Ti}) \mathrm{Cr}_{2}$ Laves phase is only $65 \mathrm{MPa}$ [13]. In contrast, the $\mathrm{BCC} / \mathrm{B} 2$ coherent microstructure with cuboidal $\mathrm{BCC}$ precipitates into the $\mathrm{B} 2$ matrix renders the $\mathrm{AlMo}_{0.5} \mathrm{NbTa}_{0.5} \mathrm{Zr}$ with a much higher HT strength $\left(\sigma_{Y S}=745 \mathrm{MPa}\right.$ at $\left.1273 \mathrm{~K}\right)$, exceeding the strength of some Ni-base superalloys [8,14]. It is emphasized that the ductility of this alloy is very low at RT, which is attributed to the brittle continuous B2 matrix $[8,9]$. Similar coherent microstructure was also found in other RHEAs, such as $\mathrm{Al}_{0.25} \mathrm{NbTaTiZr}$ [15] and $\mathrm{Al}_{0.5} \mathrm{NbTa}_{0.8} \mathrm{~V}_{0.2} \mathrm{Ti}_{1.5} \mathrm{Zr}$ [9]. Interestingly, it was reported that a 'phase inversion' phenomenon could occur in $\mathrm{Al}_{0.5} \mathrm{NbTa}_{0.8} \mathrm{~V}_{0.2} \mathrm{Ti}_{1.5} \mathrm{Zr}$ alloy during aging at $873 \mathrm{~K}$ [16], i.e., a coherent microstructure with spherical B2 nanoprecipitates into the BCC matrix could be obtained after a long-time aging, which would improve the ductility of alloy at RT and $873 \mathrm{~K}$ on a large extent without the loss of strength [16]. Actually, it was driven by the difference in elastic moduli of these two phases, in which the distribution of discrete hard particles (B2) on a continuous soft matrix (BCC) will minimize the total energy of the system for achievement of stable microstructure [17,18].

Moreover, the formation of spherical or cuboidal nanoprecipitates is controlled by the lattice misfit $\varepsilon$ between the BCC and B2 phases [19]. In our previous work on Al-Ni-Co-FeCr HEAs, we investigated the morphology evolution of precipitates with alloy compositions in the formula of $\mathrm{Al}_{2} \mathrm{M}_{14}$, in which $\mathrm{M}$ represents different combinations of transition metals of $\mathrm{Ni}, \mathrm{Co}, \mathrm{Fe}$, and $\mathrm{Cr}$ in order to adjust the lattice misfit [20-24]. It was found that a small $\varepsilon$ $(\varepsilon<0.7 \%)$ corresponds to spheroidal nanoprecipitates, a larger $\varepsilon(\varepsilon>2.0 \%)$ corresponds to a weave-like spinodal decomposition microstructure, and only a moderate $\varepsilon(0.7 \%<\varepsilon<2.0 \%)$ is contributed to the cuboidal nanoprecipitates $[8,19]$. Unfortunately, it is difficult to tune the lattice misfit into a moderate value due to a large composition difference in BCC and B2 phases. Thus, the weave-like spinodal decomposition microstructure is common in BCC/B2-based alloys, resulting in a serious brittleness $[8,19]$. Therefore, the present work will investigate the formation of $\mathrm{BCC} / \mathrm{B} 2$ coherent microstructure in Al- $\mathrm{Ti}-\mathrm{Zr}-\mathrm{Nb}$ Ta-Mo-V RHEA system with the composition formula of $\mathrm{Al}_{2} \mathrm{M}_{14}$, where $\mathrm{M}$ represents different combinations of $\mathrm{Nb}, \mathrm{Ta}, \mathrm{Ti}, \mathrm{Zr}, \mathrm{V}$, and Mo. These alloys are specifically denoted as $\mathrm{S} 0\left(\mathrm{Al}_{2} \mathrm{Ti}_{4} \mathrm{Zr}_{4} \mathrm{Nb}_{3} \mathrm{Ta}_{3}\right), \mathrm{S} 1\left(\mathrm{Al}_{2} \mathrm{Ti}_{4} \mathrm{Zr}_{4} \mathrm{Nb}_{5} \mathrm{Ta}_{1}\right), \mathrm{S} 2\left(\mathrm{Al}_{2} \mathrm{Ti}_{4} \mathrm{Zr}_{4} \mathrm{Nb}_{3} \mathrm{Ta}_{2} \mathrm{~V}_{0.5} \mathrm{Mo}_{0.5}\right)$, and S3 $\left(\mathrm{Al}_{2} \mathrm{Ti}_{5} \mathrm{Zr}_{4} \mathrm{Nb}_{2.5} \mathrm{Ta}_{2.5}\right)$, respectively, as listed in Table 1 . And the microstructural evolution of these alloys induced by different combinations of $\mathrm{M}$ will be discussed in the viewpoint of lattice misfit between the precipitates and matrix. The compressive mechanical properties of these RHEAs will also be measured.

Table 1. Data summary for the designed RHEAs at $873 \mathrm{~K}$-aged state, including nominal formula and composition in atomic percent (at. \%), phase constitutions, lattice constants (a), lattice misfit $(\varepsilon)$, particle size $(r)$ of B2 and BCC2 nanoprecipitates and compressive yield strength $\left(\sigma_{Y S}\right)$.

\begin{tabular}{|c|c|c|c|c|c|c|}
\hline No. & $\begin{array}{c}\text { Nominal Formula } \\
\text { (Composition in at. \%) }\end{array}$ & $\begin{array}{c}\text { Phase } \\
\text { Constitutions }\end{array}$ & $\begin{array}{c}a \\
(\mathrm{~nm})\end{array}$ & $\begin{array}{c}\mathcal{E} \\
(\%)\end{array}$ & $\begin{array}{c}r \\
(\mathrm{~nm})\end{array}$ & $\begin{array}{c}\sigma_{Y S} \\
(\mathrm{MPa})\end{array}$ \\
\hline So & $\begin{array}{c}\mathrm{Al}_{2} \mathrm{Ti}_{4} \mathrm{Zr}_{4} \mathrm{Nb}_{3} \mathrm{Ta}_{3} \\
\mathrm{Al}_{12.5} \mathrm{Ti}_{25.0} \mathrm{Zr}_{25.0} \mathrm{Nb}_{18.75} \mathrm{Ta}_{18.75}\end{array}$ & $\begin{array}{c}\mathrm{BCC}+\mathrm{B} 2+ \\
\mathrm{Zr}_{5} \mathrm{Al}_{3}\end{array}$ & $\begin{array}{c}a_{\mathrm{BCC}}=0.3298 \\
a_{\mathrm{B} 2}=0.3390\end{array}$ & $\varepsilon_{\mathrm{BCC} 1 / \mathrm{B} 2}=2.75$ & $20 \sim 35$ & 1400 \\
\hline $\mathrm{S} 1$ & $\begin{array}{c}\mathrm{Al}_{2} \mathrm{Ti}_{4} \mathrm{Zr}_{4} \mathrm{Nb}_{5} \mathrm{Ta}_{1} \\
\mathrm{Al}_{12.5} \mathrm{Ti}_{25.0} \mathrm{Zr}_{25.0} \mathrm{Nb}_{31.25} \mathrm{Ta}_{6.25}\end{array}$ & $\begin{array}{l}\mathrm{BCC} 1+\mathrm{BCC} 2+ \\
\mathrm{B} 2+\mathrm{Zr}_{5} \mathrm{Al}_{3}\end{array}$ & $\begin{array}{c}a_{\mathrm{BCC} 1}=0.3391 \\
a_{\mathrm{BCC} 1}=0.3439 \\
a_{\mathrm{B} 2}=0.3462\end{array}$ & $\begin{array}{l}\varepsilon_{\mathrm{BCC} 1 / \mathrm{B} 2}=2.07 \\
\varepsilon_{\mathrm{BCC} 2 / \mathrm{B} 2}=0.67\end{array}$ & $25 \sim 55$ & 1125 \\
\hline S2 & $\begin{array}{c}\mathrm{Al}_{2} \mathrm{Ti}_{4} \mathrm{Zr}_{4} \mathrm{Nb}_{3} \mathrm{Ta}_{2} \mathrm{~V}_{0.5} \mathrm{Mo}_{0.5} \mathrm{Al}_{12.5} \\
\mathrm{Ti}_{25.0} \mathrm{Zr}_{25.0} \mathrm{Nb}_{18.75} \mathrm{Ta}_{12.5} \\
\mathrm{~V}_{3.125} \mathrm{Mo}_{3.125}\end{array}$ & $\begin{array}{l}\mathrm{BCC}+\mathrm{B} 2+ \\
\mathrm{Zr}_{5} \mathrm{Al}_{3}\end{array}$ & $\begin{array}{c}a_{\mathrm{BCC}}=0.3294 \\
a_{\mathrm{B} 2}=0.3327\end{array}$ & $\varepsilon_{\mathrm{BCC} 1 / \mathrm{B} 2}=1.00$ & $25 \sim 45$ & 1150 \\
\hline S3 & $\begin{array}{c}\mathrm{Al}_{2} \mathrm{Ti}_{5} \mathrm{Zr}_{4} \mathrm{Nb}_{2.5} \mathrm{Ta}_{2.5} \\
\mathrm{Al}_{12.5} \mathrm{Ti}_{31.25} \mathrm{Zr}_{25.0} \mathrm{Nb}_{15.625} \mathrm{Ta}_{15.625}\end{array}$ & $\begin{array}{c}\mathrm{BCC} 1+\mathrm{BCC} 2+ \\
\mathrm{B} 2+\mathrm{Zr}_{5} \mathrm{Al}_{3}\end{array}$ & $\begin{array}{c}a_{\mathrm{BCC} 1}=0.3352 \\
a_{\mathrm{BCC} 2}=0.3307 \\
a_{\mathrm{B} 2}=0.3377\end{array}$ & $\begin{array}{l}\varepsilon_{\mathrm{BCC} 1 / \mathrm{B} 2}=2.09 \\
\varepsilon_{\mathrm{BCC} 2 / \mathrm{B} 2}=0.74\end{array}$ & $25 \sim 50$ & 1232 \\
\hline
\end{tabular}




\section{Materials and Methods}

The series of RHEAs, $\quad \mathrm{Al}_{2} \mathrm{Ti}_{4} \mathrm{Zr}_{4} \mathrm{Nb}_{3} \mathrm{Ta}_{3} \quad(\mathrm{~S} 0), \quad \mathrm{Al}_{2} \mathrm{Ti}_{4} \mathrm{Zr}_{4} \mathrm{Nb}_{5} \mathrm{Ta}_{1} \quad$ (S1) $\mathrm{Al}_{2} \mathrm{Ti}_{4} \mathrm{Zr}_{4} \mathrm{Nb}_{3} \mathrm{Ta}_{2} \mathrm{~V}_{0.5} \mathrm{Mo}_{0.5}$ (S2) and $\mathrm{Al}_{2} \mathrm{Ti}_{5} \mathrm{Zr}_{4} \mathrm{Nb}_{2.5} \mathrm{Ta}_{2.5}$ (S3), were prepared by means of arc-melting in a copper die under an argon atmosphere. The purities of the raw material metals are $99.99 \%$ for $\mathrm{Al}, \mathrm{Ti}$ and $\mathrm{Zr}$, and $99.95 \%$ for $\mathrm{Nb}, \mathrm{Ta}, \mathrm{V}$ and $\mathrm{Mo}$, respectively. These ingots were remelted at least five times to ensure their chemical homogeneity. These RHEAs were then sealed in vacuum quartz glass tubes and melted in a muffle furnace at $1573 \mathrm{~K}$ for $2 \mathrm{~h}$. Finally, these solid solution specimens were aged at $873 \mathrm{~K}$ for $24 \mathrm{~h}$. All cooling methods were water quenched. The crystalline structure of the alloy specimens in different treatment states was characterized using a Bruker D8 X-ray diffractometer (XRD) (Bruker, Karlsruhe, Germany) at $\mathrm{Cu} K \alpha$ radiation $(\lambda=0.15406 \mathrm{~nm})$. According to Bragg's Law, the lattice constants of phases were calculated by an external standard method [25]. The microstructural characterizations were carried employing Zeiss Supra 55 scanning electron microscopy (SEM) (Zeiss, Oberkochen, Germany) and JEM2100F FEG scanning transmission electron microscopy (STEM) (JEOL, Tokyo, Japan). The chemical composition was analyzed using SHIMADZU electronic probe micro-analyzer (EPMA) (SHIMADZU, Kyoto, Japan) and Super-X energy dispersive X-ray spectrometry (EDS) (SHIMADZU, Kyoto, Japan) detector equipped on an FEI Titan G2 60-300 Cs-corrected TEM (FEI, Hillsboro, OR, USA) operating at $300 \mathrm{kV}$. The TEM specimens were prepared by an FEI Helios NanoLab 600 Dual-Beam focused ion beam (DB-FIB) (FEI, Hillsboro, OR, USA) instrument, where the FIB lift-out and thinning procedures were described elsewhere [26]. Statistical analysis on the particle size of precipitates and volume fraction of each phase were performed with at least 5 SEM and TEM morphology images using the Image-Pro Plus 6.0 software (National Institutes of Health, Washington, DC, USA). The uniaxial compressive tests at room temperature were performed on an UTM5504 Material Test System (MTS) (Shenzhen Sanshi Zongheng Technology Co., Shenzhen, China) with three rectangular specimens of size $5 \mathrm{~mm} \times 5 \mathrm{~mm} \times 8 \mathrm{~mm}$ were tested for each treatment state at a strain rate of $1 \times 10^{-3} \mathrm{~s}^{-1}$ in each treatment state.

\section{Results and Discussions}

Figure 1 shows the XRD patterns of these four RHEAs in both solid-solutionized and $873 \mathrm{~K}$-aged states, from which it is found that all these heat-treated alloys are mainly constituted of BCC and B2 phases. The B2 phase is characterized with a weak (100) diffraction peak $\left(2 \theta \sim 26^{\circ}\right)$ in solid-solution state, and this peak becomes much more obvious after $873 \mathrm{~K}$-aging for $24 \mathrm{~h}$. Especially, there exist two kinds of BCC phases in S1 and S3 alloys, i.e., BCC1 and BCC2, as demonstrated by the diffraction peak splitting of the BCC phase. It is mainly ascribed to phase separation induced by a large composition difference. While the matrix of S0 and S2 RHEAs is constituted of one kind of BCC phase. The phase constitutions, lattice misfit $(\varepsilon)$, particle size $(r)$ of B2 and BCC phases in these RHEAs are presented in Table 1, in which the lattice misfits among B2, BCC1, and BCC2 phases in both solid-solutionized and $873 \mathrm{~K}$-aged alloys are calculated by the equation of $\varepsilon=2 \times\left(a_{\mathrm{B} 2}-a_{\mathrm{BCC}}\right) /\left(a_{\mathrm{B} 2}+a_{\mathrm{BCC}}\right)$. The lattice misfits of these RHEAs are in a range of $0.6 \sim 2.8 \%$, which is crucial to the formation of BCC/B2 coherent microstructure. This will be discussed in next section. 

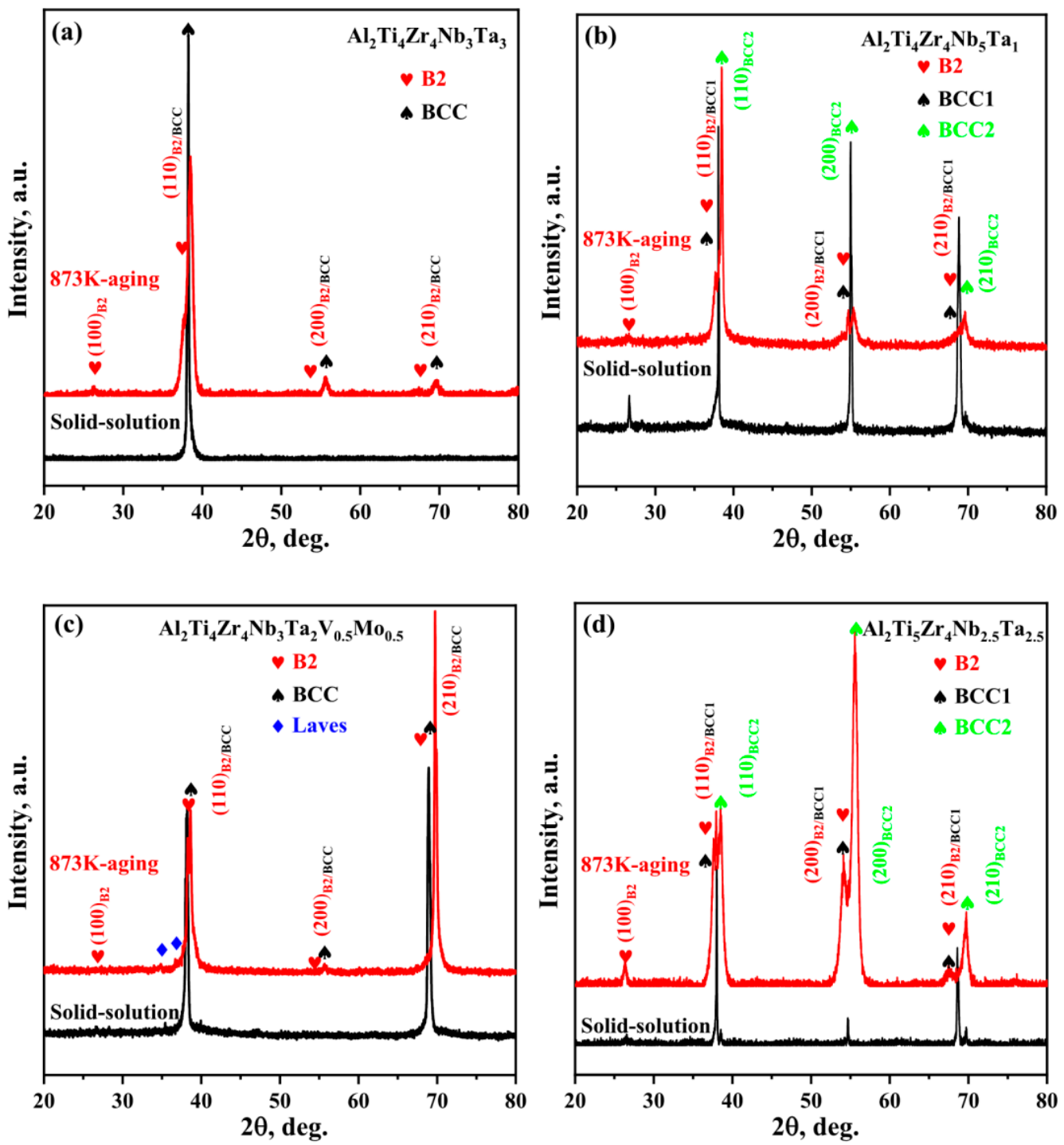

Figure 1. XRD patterns of the series RHEAs at solid-solutioned and $873 \mathrm{~K}$-aged states. (a-d): S0, S1, S2 and S3, respectively.

Microstructural characterizations with the SEM back-scattered electron (BSE) images of these designed RHEAs after $873 \mathrm{~K}$-aging were presented in Figure 2. It is obvious that the microstructures of these RHEAs are composed of the bright and dark regions due to the Z-contrast. Combined with the XRD results, the bright and dark regions in the matrix of $\mathrm{S} 1$ and $\mathrm{S} 3$ alloys are identified as $\mathrm{BCC} 1$ and $\mathrm{BCC} 2$ phases, respectively. And the matrix of S0 and S2 RHEAs is only one kinds of BCC phase. Considering that both the $\mathrm{B} 2$ and $\mathrm{Zr}_{5} \mathrm{Al}_{3}$ phases are enriched in $\mathrm{Al}$ and $\mathrm{Zr}$, which have lower value of $Z$, the dark region should represent $\mathrm{B} 2$ and $\mathrm{Zr}_{5} \mathrm{Al}_{3}$ nanoparticles [27]. The bright region represents the BCC2 $(\mathrm{Nb} / \mathrm{Ta}$-rich) phase particles, which will be identified by the following Super-X EDS mapping. Moreover, it seems that all the $\mathrm{B} 2, \mathrm{Zr}_{5} \mathrm{Al}_{3}$, and $\mathrm{BCC} 2$ particles in a cuboidal shape with a size of about $25 \sim 50 \mathrm{~nm}$ are precipitated in the BCC1 matrix of S1 and S3 alloys, which is consistent with XRD results. It is noted that the microstructures of these RHEAs on the grain boundaries is much coarser. However, there is no other new precipitated phases. Except the S0 alloy, other three RHEAs seem to have a better microstructure with $\mathrm{BCC} / \mathrm{B} 2$ coherent microstructure due to a moderate lattice misfit of $\varepsilon=0.7 \sim 2.0 \%$ (Table 1 ). 

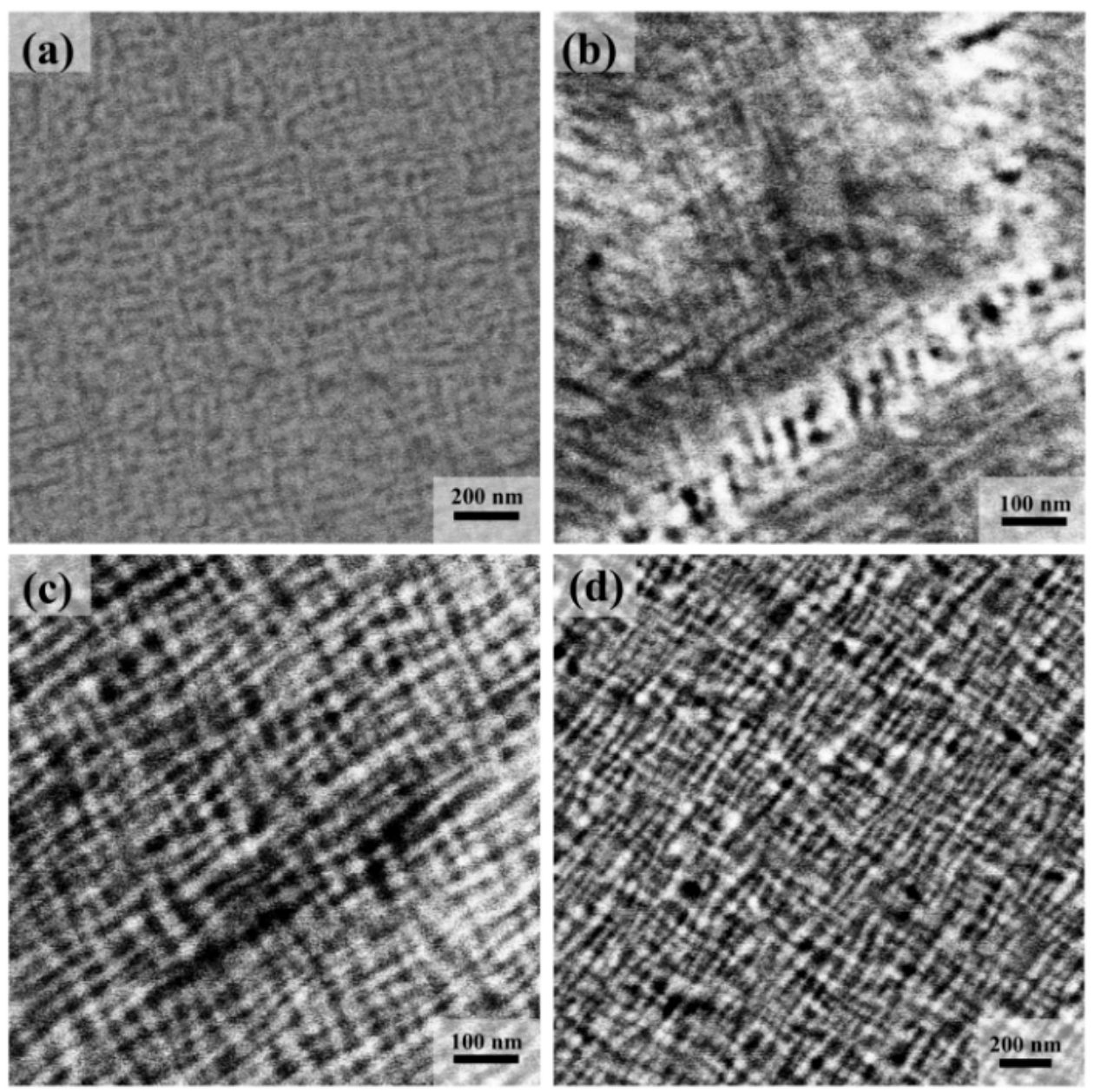

Figure 2. SEM back-scattered images of RHEAs at $873 \mathrm{~K}$-aged state. (a-d): S0, S1, S2 and S3, respectively.

In order to further identify the crystalline structures of nanoprecipitates, the S3$\mathrm{Al}_{2} \mathrm{Ti}_{5} \mathrm{Zr}_{4} \mathrm{Nb}_{2.5} \mathrm{Ta}_{2.5}$ alloy in both solid-solutionized and $873 \mathrm{~K}$-aged states was analyzed by the TEM, as shown in Figure 3. In the solid-solutionized state, there exist spherical B2 nanoparticles with a size of $3 \sim 5 \mathrm{~nm}$ precipitated in the BCC matrix, which is identified with both the dark-field (DF) image and the corresponding selected area electron diffraction (SAED) pattern along the [110 $]_{B C C}$ direction (Figure 3a). After aging at $873 \mathrm{~K}$ for $24 \mathrm{~h}$, these B2 nanoparticles are gradually coarsened to the size of about $25 \sim 35 \mathrm{~nm}$ and exhibit a cuboidal shape, as shown in the TEM-DF image in Figure 3b. Moreover, another hexagonal $\mathrm{Zr}_{5} \mathrm{Al}_{3}$ phase co-precipitates with the $\mathrm{B} 2$, as demonstrated by the SAED pattern along the $[110]_{B C C}$ direction in Figure 3. The DF images for these two kinds of nanoprecipitates are shown in Figure $3 c, d$, respectively. As an equilibrium stable phase, $\mathrm{Zr}_{5} \mathrm{Al}_{3}$ phase has a D8 8 -type $\mathrm{M}_{5} \mathrm{Si}_{3}$ structure, and has a similar composition with the metastable B2-ZrAl phase. Thus, $\mathrm{Zr}_{5} \mathrm{Al}_{3}$ phase could be transformed to the $\mathrm{B} 2$ phase under the combined effect of lattice collapse and chemical ordering of the $\{111\}$ layer in the $B 2$ phase [28]. In other words, both $\mathrm{B} 2$ and $\mathrm{Zr}_{5} \mathrm{Al}_{3}$ nanoprecipitates are co-exists in the $\mathrm{BCC}$ matrix. In order to reveal the interfacial coherency between BCC matrix and precipitates, the high-resolution TEM (HRTEM) image and fast Fourier transform (FFT) patterns along the [100] $]_{\mathrm{BCC}}$ direction shown in Figure $4 \mathrm{a}-\mathrm{c}$ showing the interface of BCC and B2 precipitate (marked with a red dash line). It exhibits a perfect interfacial coherence between BCC and B2 phases, which could maintain the stable presence of B2 phase and inhibit the coarsening of B2 phase. 

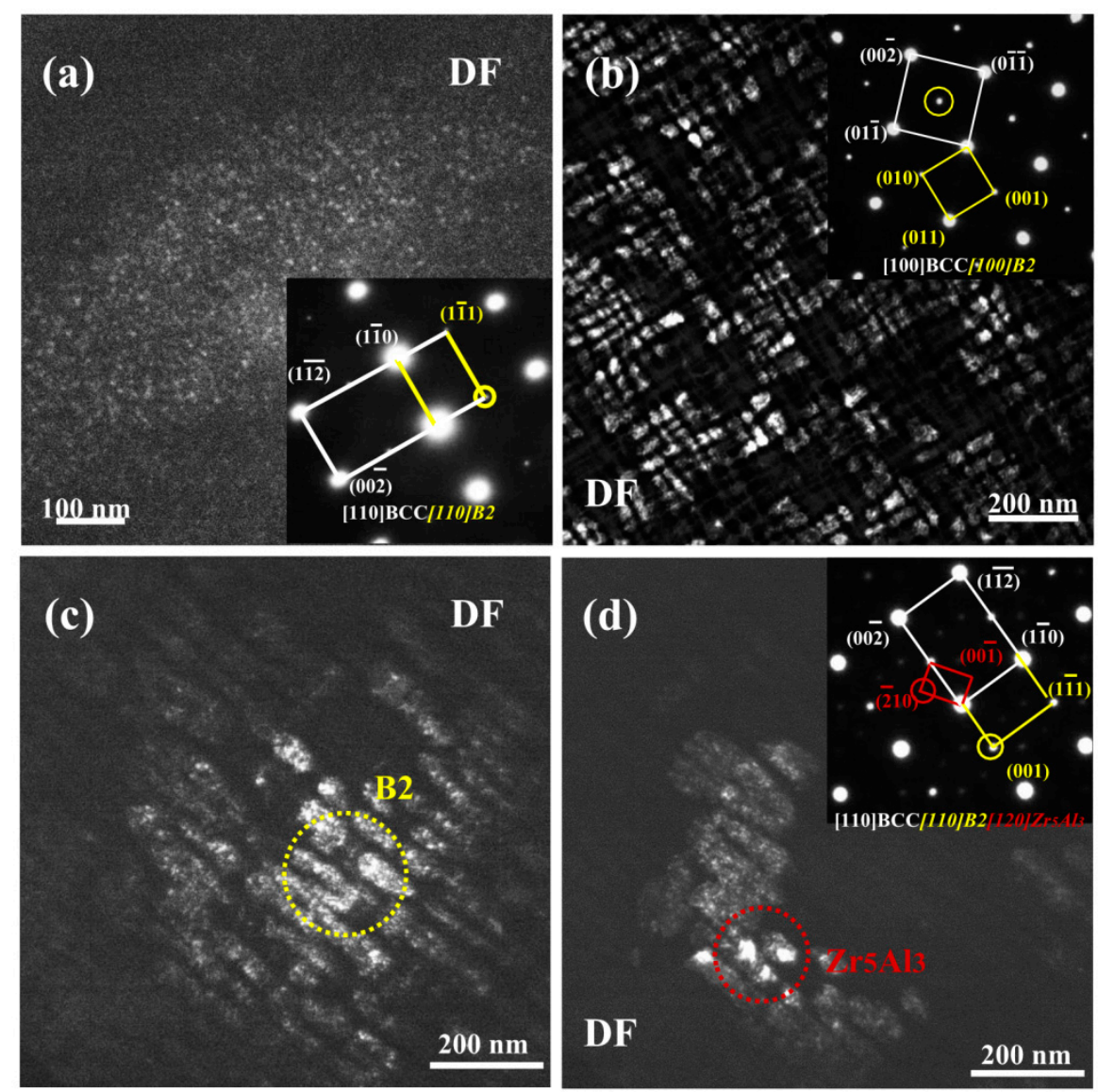

Figure 3. TEM characterization of S3 RHEA in solid-solutioned (a) and $873 \mathrm{~K}$-aging (b-d) states. tEM dark field (DF) images (a) and corresponding SAED patterns along the $[110]_{\text {BCC }}$ axis; TEM dark field (DF) images (b) and corresponding SAED patterns along the $[100]_{\mathrm{BCC}}$ axis; TEM dark field $(\mathrm{DF})$ images $(\mathbf{c}, \mathbf{d})$ and corresponding SAED patterns along the $[110]_{\mathrm{BCC}}$ axis for the corresponding SAED patterns.

For investigating the relations among these four phases of $\mathrm{BCC} 1, \mathrm{BCC}$, $\mathrm{B} 2$ and $\mathrm{Zr}_{5} \mathrm{Al}_{3}$ of S3 RHEA at $873 \mathrm{~K}$-aged state, the HAADF-STEM image and the corresponding elemental maps by the Super-X EDS are shown in Figure 5. Table 2 gives the element composition (at. \%) of each phase of the $873 \mathrm{~K}$-aged S3 RHEA. According to the XRD results, the aged S3 RHEA alloy exhibits two kinds of BCC phases, which is determined to be BCC1 and BCC2 phase, respectively. It is consistent with the SEM BSE results. It is obvious that the microstructures of these RHEAs are composed of the bright and dark regions due to the Z-contrast. Similarly, the HAADF-STEM in Figure 5 shows that the difference of $Z$-contrast. It is found that except for some precipitates, in the BCC-relevant regions the Ti element is distributed consistently. In the Ti-poor regions marked with red circles, these precipitates are mainly enriched in $\mathrm{Al}$ and $\mathrm{Zr}$ elements with an average composition of $\mathrm{Al}_{39.4} \mathrm{Nb}_{11.1} \mathrm{Ta}_{1.5} \mathrm{Ti}_{9.1} \mathrm{Zr}_{38.9}$ (at. \%, in Table 2). In the regions marked with yellow circles, the nanoparticles are also primarily segregated by the Ti element, as well as $\mathrm{Zr}$ and $\mathrm{Al}$, with an average composition of $\mathrm{Al}_{30.0} \mathrm{Nb}_{12.7} \mathrm{Ta}_{2.4} \mathrm{Ti}_{21.4} \mathrm{Zr}_{33.5}$ (at. \%). Therefore, the former is identified as the $\mathrm{Zr}_{5} \mathrm{Al}_{3}$ phase and the latter is the $\mathrm{B} 2$ phase, respectively, since the differences between them are the segregation of $\mathrm{Ti}$ in $\mathrm{B} 2$ and the much more amount of $\mathrm{Al}$ in $\mathrm{Zr}_{5} \mathrm{Al}_{3}$. The regions marked with white rectangles in HAADF of Figure 5 are enriched by $\mathrm{Ti}$ and $\mathrm{Zr}$, especially the $\mathrm{Ti}$, where $\mathrm{Ta}, \mathrm{Al}$ and $\mathrm{Nb}$ elements are depleted severely, determined to the BCC1 phase with the composition of $\mathrm{Al}_{5.4} \mathrm{Nb}_{9.1} \mathrm{Ta}_{2.2} \mathrm{Ti}_{53.0} \mathrm{Zr}_{30.3}$ (at. \%). In addition, the bright regions marked with green circles are primarily segregated by $\mathrm{Nb}$ and Ta elements, which is consistent with the BCC2 particles in a cuboidal shape with the composition of $\mathrm{Al}_{7.9} \mathrm{Nb}_{26.0} \mathrm{Ta}_{22.6} \mathrm{Ti}_{33.4} \mathrm{Zr}_{10.1}$ (at. \%). 

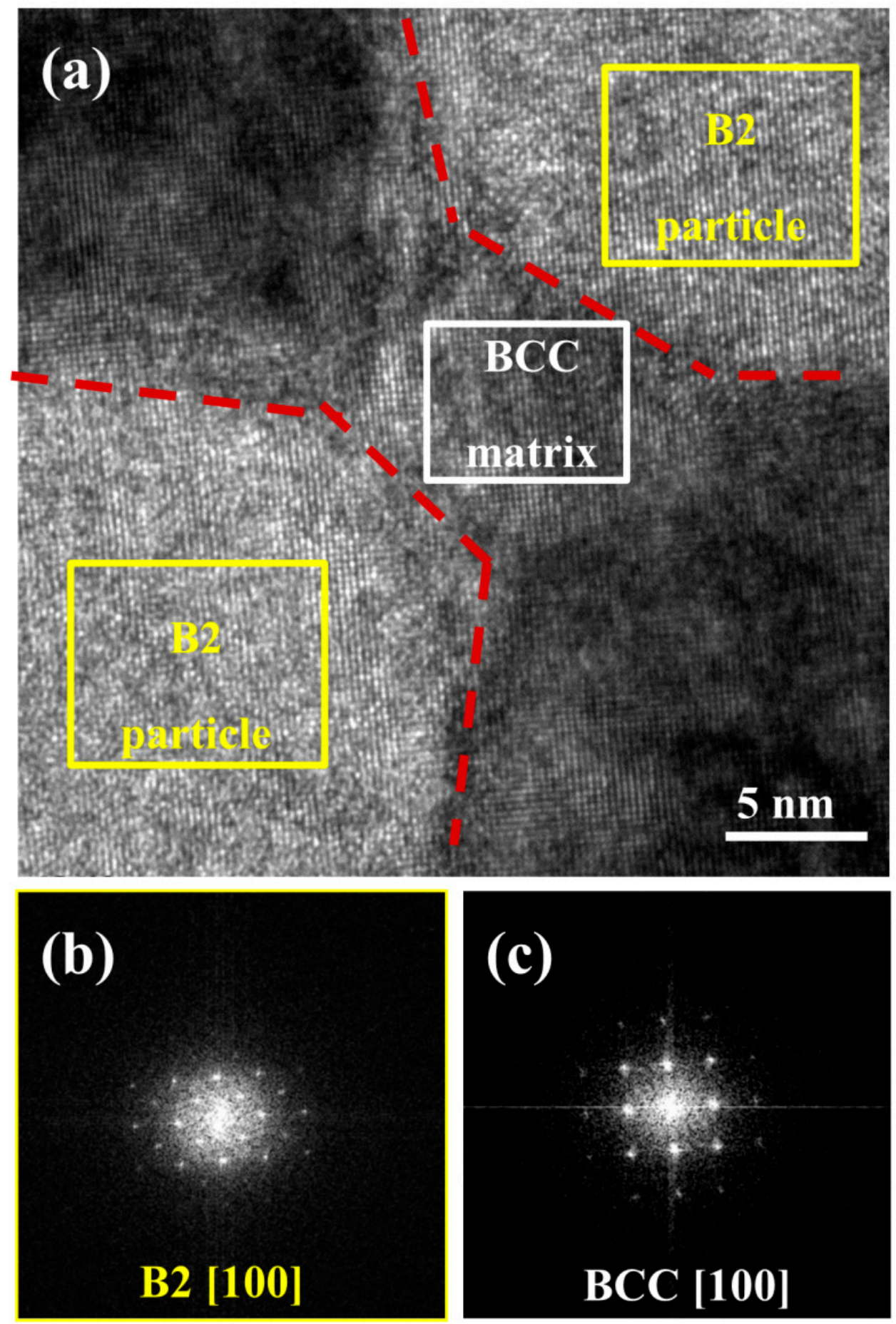

Figure 4. HRTEM images of S3 RHEA at $873 \mathrm{~K}$-aged state along the $[100]_{\mathrm{BCC}}$ zone axis. (a): the HRTEM image showing the interfaces between the BCC matrix and cuboidal B2 nanoprecipitate; $(\mathbf{b}, \mathbf{c})$ : the FFT patterns of B2 and BCC matrix nanoprecipitates, respectively. 


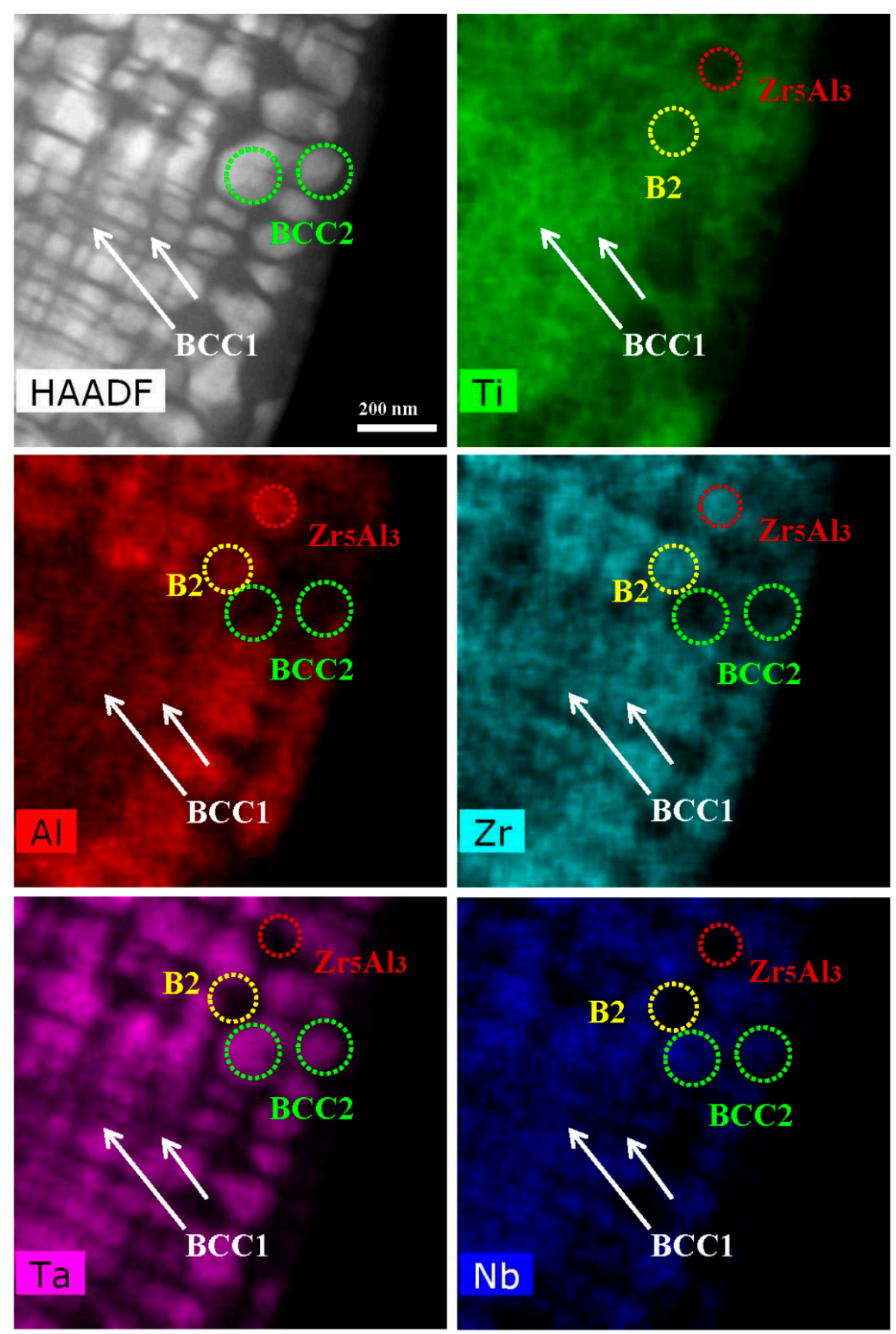

Figure 5. HAADF-STEM image and the corresponding elemental maps of the S3 RHEA after aging at $873 \mathrm{~K}$ by the Super-X EDS.

Table 2. Phase constitution and elemental composition (at. \%) in phase of the aged S3 RHEA at $873 \mathrm{~K}$ for $24 \mathrm{~h}$.

\begin{tabular}{ccccccc}
\hline \multirow{2}{*}{$\begin{array}{c}\text { Heat } \\
\text { Treatment }\end{array}$} & $\begin{array}{c}\text { Phase } \\
\text { Constitution }\end{array}$ & \multicolumn{5}{c}{ Elemental Composition in Phase (at. \%) } \\
\cline { 2 - 6 } & $\mathrm{Al}$ & $\mathbf{N b}$ & $\mathbf{T a}$ & $\mathbf{T i}$ & $\mathbf{Z r}$ \\
\hline & $\mathrm{BCC} 1$ & $5.4 \pm 1.3$ & $9.1 \pm 2.6$ & $2.2 \pm 1.0$ & $53.0 \pm 4.5$ & $30.3 \pm 0.4$ \\
\cline { 2 - 6 } & $\mathrm{BCC} 2$ & $7.9 \pm 2.7$ & $26.0 \pm 2.5$ & $22.6 \pm 1.7$ & $33.4 \pm 2.0$ & $10.1 \pm 1.2$ \\
\cline { 2 - 6 } $873 \mathrm{~K} / 24 \mathrm{~h}$ & $\mathrm{~B} 2$ & $30.0 \pm 1.2$ & $12.7 \pm 0.7$ & $2.4 \pm 0.7$ & $21.4 \pm 3.5$ & $33.5 \pm 3.0$ \\
\cline { 2 - 7 } & $\mathrm{Zr}_{5} \mathrm{Al}_{3}$ & $39.4 \pm 2.3$ & $11.1 \pm 1.5$ & $1.5 \pm 0.5$ & $9.1 \pm 3.1$ & $38.9 \pm 0.7$ \\
\hline
\end{tabular}


It is hard to obtain a stable BCC/B2 coherent microstructure in these alloy systems containing $\mathrm{Al}$ and early transition metals (ETM), because the B2 phase is metastable in any Al-ETM binary phase diagram [29]. Therefore, the BCC/B2 coherent microstructure might be stabilized only by simultaneous multicomponent alloying of BCC and B2 phases. More significantly, the morphology of the coherent particles depends strongly on the lattice misfit between the BCC and B2 phases [26]. With increasing lattice misfit, small-sized spherical or ellipsoidal nanoparticles can evolve into large-sized cuboidal particles [30,31], as confirmed by our previous work that cuboidal B2 nanoparticles are embedded into the BCC matrix in $\mathrm{Al}_{0.7} \mathrm{CoCrFe}_{2} \mathrm{Ni}$ HEA [20]. Lots of existing works on particle morphology also verify this issue, in which a moderate lattice misfit of $\varepsilon=0.7 \sim 2.0 \%$ are consistent with cuboidal nanoprecipitation in RHEAs [8,19]. It should be emphasized that in the present work, the dual-phase of $\mathrm{BCC} 2$ and $\mathrm{B} 2$ nanoprecipitation in another $\mathrm{BCC} 1$ matrix is different from previous $\mathrm{BCC}$ nanoprecipitation in $\mathrm{B} 2$ matrix [8]. Indeed, the excessive addition of $\mathrm{Al}$ could induce the formation of $\mathrm{B} 2$ matrix, as evidenced by the fact of the $\mathrm{BCC}$ nanoprecipitates in $\mathrm{B} 2$ matrix of $\mathrm{AlNi}_{2} \mathrm{Co}_{2} \mathrm{Fe}_{1.5} \mathrm{Cr}_{1.5}$ alloy [19]. Furthermore, in the aged S3 alloy, both $\mathrm{B} 2$ and $\mathrm{Zr}_{5} \mathrm{Al}_{3}$ phases coexist in the BCC matrix. However, it is difficult to distinguish the particle morphology of $\mathrm{B} 2$ and $\mathrm{Zr}_{5} \mathrm{Al}_{3}$ phases because of their tight association.

The room temperature compressive properties of the designed RHEAs in both solidsolutionized and $873 \mathrm{~K}$-aged states were then performed. Figure 6 shows the true stressstrain curves, and the measured yield strength values of these RHEAs are listed in Table 1. The solid-solutionized RHEAs exhibit not only high yield strength $\left(\sigma_{Y S}=920 \sim 1050 \mathrm{MPa}\right)$, but also larger compressive plasticity over $15 \%$, which is attributed to the ultra-fine spherical B2 nanoprecipitates embedded into the BCC matrix. After aging at $873 \mathrm{~K}$ for $24 \mathrm{~h}$, the strength of aged RHEAs could be enhanced up to $\sigma_{Y S}=1125 \sim 1400 \mathrm{MPa}$, which is comparable to that $\left(\sigma_{Y S}=1125 \sim 1400 \mathrm{MPa}\right)$ of the existing $\mathrm{Al}_{10} \mathrm{Nb}_{15} \mathrm{Ta}_{5} \mathrm{Ti}_{30} \mathrm{Zr}_{40}$ RHEA with similar heat treatments $[32,33]$. However, the plasticity of aged alloys is decreased down to below $10 \%$, which might be related to the heterogeneity of microstructure, i.e., another kind of $\mathrm{Zr}_{5} \mathrm{Al}_{3}$ particles coexists with $\mathrm{B} 2$ and the $\mathrm{BCC}$ matrix separates into two phases after aging.
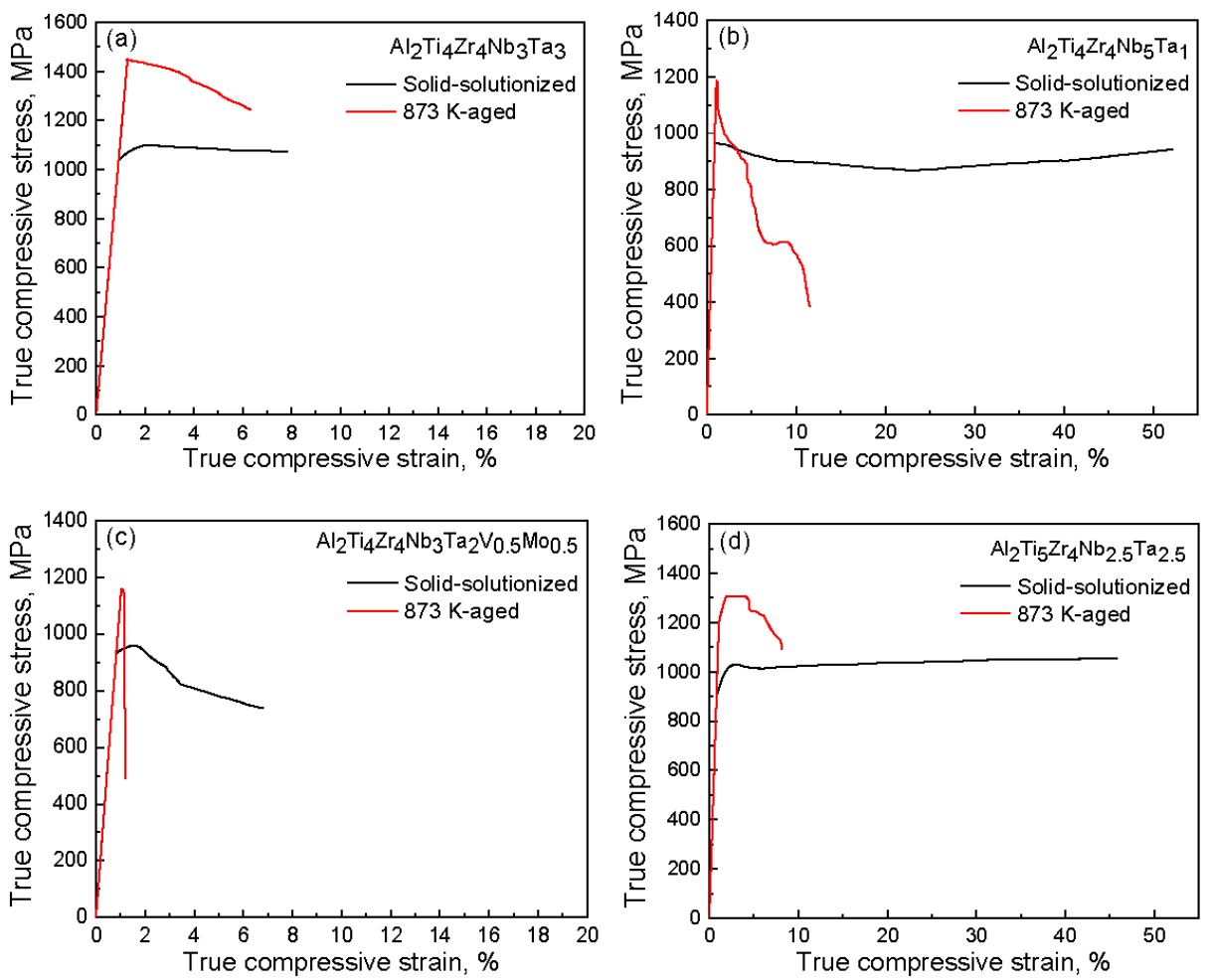

Figure 6. True compressive stress-strain curves of RHEAs at solid-solutioned and $873 \mathrm{~K}$-aged states. (a-d): S0, S1, S2 and S3, respectively. 


\section{Conclusions}

In this series of Ai-Ti-Zr-Nb-Ta-Mo-V alloys, the coherent microstructure with the ordered $\mathrm{B} 2$ phase precipitated are found in the BCC matrix. There exists phase separation of BCC among RHEAs, Ti/Zr-rich BCC1 and $\mathrm{Nb}$ /Ta-rich BCC2. After the solid-solutionized treatment, ultrafine spherical B2 nanoprecipitates $(3 \sim 5 \mathrm{~nm})$ are dispersed in the $\mathrm{Nb} / \mathrm{Ta}$-rich BCC2 matrix. these B2 nanoparticles could be coarsened up to $25 \sim 50 \mathrm{~nm}$ after aging at $873 \mathrm{~K}$ for $24 \mathrm{~h}$, and exhibit a cuboidal shape due to a moderate lattice misfit $(\varepsilon=0.7 \sim 2.0 \%)$. In addition, the cuboidal BCC2 particles are coherently-precipitated in the BCC1 matrix with a similar size of about $25 \sim 50 \mathrm{~nm}$ in $873 \mathrm{~K}$-aged alloys. $\mathrm{Zr}_{5} \mathrm{Al}_{3}$ co-exists with the $\mathrm{B} 2$ phase, and the difference between them is that $\mathrm{Ti}$ is enriched in $\mathrm{B} 2$ rather than in $\mathrm{Zr}_{5} \mathrm{Al}_{3}$. The higher strength and larger compressive plasticity of $\mathrm{Al}_{2} \mathrm{Ti}_{5} \mathrm{Zr}_{4} \mathrm{Nb}_{2.5} \mathrm{Ta}_{2.5}$ RHEA is primarily attributed to the coherent precipitation in the $\mathrm{BCC}$ matrix. The reduction of the phase separation of the $\mathrm{BCC}$ matrix and the amount of non-coherent $\mathrm{Zr}_{5} \mathrm{Al}_{3}$ phase would further improve mechanical properties of RHEAs.

Author Contributions: Investigation, methodology, writing—original draft, formal analysis, Z.W.; data curation, D.J. and J.H.; supervision, conceptualization, writing-review and editing, Q.W.; conceptualization, Z.Z.; writing-review and editing, resources, C.D. All authors have read and agreed to the published version of the manuscript.

Funding: This research was funded by the National Natural Science Foundation of China, grant number 91860108 and U1867201 and Natural Science Foundation of Liaoning Province of China, grant number 2019-KF-05-01.

Conflicts of Interest: The authors declare no conflict of interest.

\section{References}

1. Cantor, B.; Chang, I.; Knight, P.; Vincent, A. Microstructural development in equiatomic multicomponent alloys. Mater. Sci. Eng. A 2004, 375-377, 213-218. [CrossRef]

2. Chen, T.-K.; Shun, T.; Yeh, J.; Wong, M. Nanostructured nitride films of multi-element high-entropy alloys by reactive DC sputtering. Surf. Coat. Technol. 2004, 188-189, 193-200. [CrossRef]

3. Gao, M.C.; Liaw, P.K.; Yeh, J.W.; Zhang, Y. High-Entropy Alloys; Springer, International Publishing: Cham, Switzerland, 2016.

4. Zhang, Y.; Zuo, T.T.; Tang, Z.; Gao, M.C.; Dahmen, K.A.; Liaw, P.K.; Lu, Z.P. Microstructures and properties of high-entropy alloys. Prog. Mater. Sci. 2014, 61, 1-93. [CrossRef]

5. Senkov, O.; Wilks, G.; Scott, J.; Miracle, D. Mechanical properties of $\mathrm{Nb}_{25} \mathrm{Mo}_{25} \mathrm{Ta}_{25} \mathrm{~W}_{25}$ and $\mathrm{V}_{20} \mathrm{Nb}_{20} \mathrm{Mo}_{20} \mathrm{Ta}_{20} \mathrm{~W}_{20}$ refractory high entropy alloys. Intermetallics 2011, 19, 698-706. [CrossRef]

6. Senkov, O.; Scott, J.M.; Senkova, S.V.; Meisenkothen, F.; Miracle, D.B.; Woodward, C.F. Microstructure and elevated temperature properties of a refractory TaNbHfZrTi alloy. J. Mater. Sci. 2012, 47, 4062-4074. [CrossRef]

7. Senkov, O.; Senkova, S.; Miracle, D.; Woodward, C. Mechanical properties of low-density, refractory multi-principal element alloys of the Cr-Nb-Ti-V-Zr system. Mater. Sci. Eng. A 2013, 565, 51-62. [CrossRef]

8. Senkov, O.N.; Isheim, D.; Seidman, D.N.; Pilchak, A.L. Development of a Refractory High Entropy Superalloy. Entropy 2016, 18, 102. [CrossRef]

9. Senkov, O.N.; Woodward, C.; Miracle, D.B. Microstructure and Properties of Aluminum-Containing Refractory High-Entropy Alloys. JOM 2014, 66, 2030-2042. [CrossRef]

10. Wu, Y.; Cai, Y.; Chen, X.; Wang, T.; Si, J.; Wang, L.; Wang, Y.; Hui, X. Phase composition and solid solution strengthening effect in TiZrNbMoV high-entropy alloys. Mater. Des. 2015, 83, 651-660. [CrossRef]

11. Stepanov, N.D.; Yurchenko, N.Y.; Shaysultanov, D.; Salishchev, G.; Tikhonovsky, M.A. Effect of Al on structure and mechanical properties of AlxNbTiVZr (x=0, 0.5, 1, 1.5) high entropy alloys. Mater. Sci. Technol. 2015, 31, 1184-1193. [CrossRef]

12. Guo, N.; Wang, L.; Luo, L.; Li, X.; Chen, R.; Su, Y.; Guo, J.; Fu, H. Microstructure and mechanical properties of refractory high entropy $\left(\mathrm{Mo}_{0.5} \mathrm{NbHf}_{0.5} \mathrm{ZrTi}\right)_{\mathrm{BCC}} / \mathrm{M}_{5} \mathrm{Si}_{3}$ in-situ compound. J. Alloys Compd. 2016, 660, 197-203. [CrossRef]

13. Senkov, O.; Woodward, C. Microstructure and properties of a refractory $\mathrm{NbCrMo}_{0.5} \mathrm{Ta}_{0.5} \mathrm{TiZr}_{\mathrm{Zlloy}}$. Mater. Sci. Eng. A 2011, 529, 311-320. [CrossRef]

14. Lei, Z.; Liu, X.; Wu, Y.; Wang, H.; Jiang, S.; Wang, S.; Hui, X.; Wu, Y.; Gault, B.; Kontis, P.; et al. Enhanced strength and ductility in a high-entropy alloy via ordered oxygen complexes. Nat. Cell Biol. 2018, 563, 546-550. [CrossRef] [PubMed]

15. Senkov, O.; Jensen, J.; Pilchak, A.; Miracle, D.; Fraser, H. Compositional variation effects on the microstructure and properties of a refractory high-entropy superalloy $\mathrm{AlMo}_{0.5} \mathrm{NbTa}_{0.5} \mathrm{TiZr}$. Mater. Des. 2018, 139, 498-511. [CrossRef]

16. Soni, V.; Gwalani, B.; Alam, T.; Dasari, S.; Zheng, Y.; Senkov, O.; Miracle, D.; Banerjee, R. Phase inversion in a two-phase, BCC+B2, refractory high entropy alloy. Acta Mater. 2020, 185, 89-97. [CrossRef] 
17. Jensen, J.; Welk, B.; Williams, R.; Sosa, J.; Huber, D.; Senkov, O.; Viswanathan, G.; Fraser, H. Characterization of the microstructure of the compositionally complex alloy $\mathrm{Al1Mo}_{0.5} \mathrm{Nb}_{1 \mathrm{Ta}} \mathrm{T}_{0.5} \mathrm{Ti}_{1} \mathrm{Zr}_{1}$. Scr. Mater. 2016, 121, 1-4. [CrossRef]

18. Soni, V.; Gwalani, B.; Senkov, O.; Viswanathan, B.; Alam, T.; Miracle, D.B.; Banerjee, R. Phase stability as a function of temperature in a refractory high-entropy alloy. J. Mater. Res. 2018, 33, 3235-3246. [CrossRef]

19. Ma, Y.; Wang, Q.; Jiang, B.; Li, C.; Hao, J.; Li, X.; Dong, C.; Nieh, T. Controlled formation of coherent cuboidal nanoprecipitates in body-centered cubic high-entropy alloys based on $\mathrm{Al}_{2}(\mathrm{Ni}, \mathrm{Co}, \mathrm{Fe}, \mathrm{Cr})_{14}$ compositions. Acta Mater. 2018, 147, 213-225. [CrossRef]

20. Wang, Q.; Ma, Y.; Jiang, B.; Li, X.; Shi, Y.; Dong, C.; Liaw, P.K. A cuboidal B2 nanoprecipitation-enhanced body-centered-cubic alloy Al0.7CoCrFe2Ni with prominent tensile properties. Scr. Mater. 2016, 120, 85-89. [CrossRef]

21. Ma, Y.; Wang, Q.; Li, C.; Santodonato, L.J.; Feygenson, M.; Dong, C.; Liaw, P.K. Chemical short-range orders and the induced structural transition in high-entropy alloys. Scr. Mater. 2018, 144, 64-68. [CrossRef]

22. Li, C.; Ma, Y.; Hao, J.; Yan, Y.; Wang, Q.; Dong, C.; Liaw, P.K. Microstructures and mechanical properties of body-centered-cubic $(\mathrm{Al}, \mathrm{Ti})_{0.7}(\mathrm{Ni}, \mathrm{Co}, \mathrm{Fe}, \mathrm{Cr})_{5}$ high entropy alloys with coherent B2/L2 1 nanoprecipitation. Mater. Sci. Eng. A 2018, 737, 286-296. [CrossRef]

23. Ma, Y.; Hao, J.; Wang, Q.; Zhang, C.; Li, C.; Dong, C. Temperature-affected microstructural stability of coherent cuboidal B2

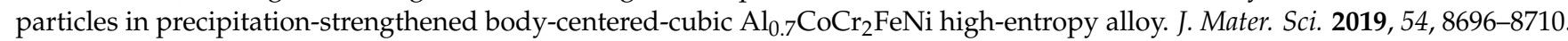
[CrossRef]

24. Ma, Y.; Jiang, B.; Li, C.; Wang, Q.; Dong, C.; Liaw, P.K.; Xu, F.; Sun, L. The BCC/B2 Morphologies in AlxNiCoFeCr High-Entropy Alloys. Metals 2017, 7, 57. [CrossRef]

25. Cullity, D.B.; Stock, S.R. Elements of X-ray Diffraction, 3rd ed.; Prentice Hall: Hoboken, NJ, USA, 2001.

26. Sosa, J.M.; Jensen, J.K.; Huber, D.E.; Viswanathan, G.B.; Gibson, M.A.; Fraser, H.L. Three-dimensional characterisation of the microstructure of an high entropy alloy using STEM/HAADF tomography. Mater. Sci. Technol. 2015, 31, 1250-1258. [CrossRef]

27. Wang, Q.; Han, J.C.; Zhang, Z.W.; Dong, C.; Liaw, P.K. Coherent precipitation and stability of cuboidal nanoparticles in body-centered-cubic $\mathrm{Al}_{0.4} \mathrm{Nb}_{0.5} \mathrm{Ta}_{0.5} \mathrm{TiZr}_{0.8}$ refractory high entropy alloy. Scr. Mater. 2021, 190, 40-45. [CrossRef]

28. Bendersky, L.; Boettinger, W.; Burton, B.; Biancaniello, F.; Shoemaker, C. The formation of ordered $\omega$-related phases in alloys of composition $\mathrm{Ti}_{4} \mathrm{Al}_{3} \mathrm{Nb}$. Acta Met. Mater. 1990, 38, 931-943. [CrossRef]

29. Cramer, S.D.; Covino, B.S., Jr. ASM Handbook; ASM International: Almere, The Netherlands, 2005; Volume 13B.

30. Voorhees, P.; McFadden, G.; Johnson, W. On the morphological development of second-phase particles in elastically-stressed solids. Acta Met. Mater. 1992, 40, 2979-2992. [CrossRef]

31. Thompson, M.; Su, C.; Voorhees, P. The equilibrium shape of a misfitting precipitate. Acta Met. Mater. 1994, 42, $2107-2122$. [CrossRef]

32. Soni, V.; Senkov, O.N.; Gwalani, B.; Miracle, D.B.; Banerjee, R. Microstructural Design for Improving Ductility of An Initially Brittle Refractory High Entropy Alloy. Sci. Rep. 2018, 8, 8816. [CrossRef]

33. Soni, V.; Senkov, O.; Couzinie, J.-P.; Zheng, Y.; Gwalani, B.; Banerjee, R. Phase stability and microstructure evolution in a ductile refractory high entropy alloy $\mathrm{Al}_{10} \mathrm{Nb}_{15} \mathrm{Ta}_{5} \mathrm{Ti}_{30} \mathrm{Zr}_{40}$. Materialia 2020, 9, 100569. [CrossRef] 